\title{
Application of Factorial Design of Experiment for Optimization of Inhibition Effect of Acid Extract of Gnetum africana on Copper Corrosion
}

\author{
Ogbonna Chris Nkuzinna1, Matthew Chukwudi Menkiti2*, Okechukwu Dominic Onukwuli², \\ Gordian Onyebuchukwu Mbah³, Bernard Ibezim Okolo4, Melford Chuka Egbujor'1, \\ Rabboni Mike Government ${ }^{2}$ \\ ${ }^{1}$ Department of Industrial Chemistry, Renaissance University, Ugbawka, Nigeria \\ ${ }^{2}$ Department of Chemical Engineering, Nnamdi Azikiwe University, Awka, Nigeria \\ ${ }^{3}$ Department of Chemical Engineering, Enugu State University of Science and Technology, Enugu, Nigeria \\ ${ }^{4}$ Department of Chemical Engineering, Michael Okpara University of Agriculture, Umudike, Nigeria \\ Email: cmenkiti@yahoo.com
}

Received 19 February 2014; revised 23 March 2014; accepted 11 April 2014

Copyright (C) 2014 by authors and Scientific Research Publishing Inc.

This work is licensed under the Creative Commons Attribution International License (CC BY).

http://creativecommons.org/licenses/by/4.0/

\section{Abstract}

The inhibition of copper corrosion by acid extract of Gnetum africana was studied using weight loss method of monitoring corrosion rate. The inhibition of Gnetum africana on copper corrosion was optimized by application of $2^{3}$ factorial design. While the interactive effects of temperature, inhibition concentration and reaction time were investigated, the input factors and output response were also optimized. Optimum conditions for inhibition of Gnetum africana on copper corrosion were recorded at temperature of $303 \mathrm{~K}$, reaction time of $24 \mathrm{~h}$ and inhibition concentration of $0.003 \mathrm{~g} / \mathrm{L}$. It could be concluded that factorial design was adequately applicable in the optimization of process variables and that Gnetuma africana sufficiently inhibited the corrosion of copper at the conditions of the experiment.

\section{Keywords}

Corrosion Inhibition, Gnetum africana, Copper, Optimization

\footnotetext{
${ }^{*}$ Corresponding author.
}

How to cite this paper: Nkuzinna, O.C., et al. (2014) Application of Factorial Design of Experiment for Optimization of Inhibition Effect of Acid Extract of Gnetum africana on Copper Corrosion. Natural Resources, 5, 299-307. 


\section{Introduction}

Copper and its alloys are good corrosion resistant in water and have excellent heat conductivity, but readily corrode in acid solutions. Copper and its alloys are broadly used in heating systems and condensers [1]. However, these systems should be regularly cleaned due to inlays of carbonates and oxides. Dilute acids are normally used to clean these surfaces. In order to prevent the corrosion of copper metals, corrosion inhibitors are generally added to the acids. The use of inhibitors is an important method of protecting materials against deterioration. Inhibitors are chemicals that often work by adsorbing themselves on the metallic surface by forming a film [2]-[6]. Most corrosion inhibitors are either synthesized from cheap raw materials or are chosen from organic compounds containing electronegative functional groups and $\pi$-electrons in triple or conjugated double bonds. The sites of aromatic rings and hetero atoms (such as $\mathrm{S}, \mathrm{N}, \mathrm{O}$ and $\mathrm{P}$ ) are the major adsorption centers for these inhibitors [7]. Broad spectra of organic compounds are available as corrosion inhibitors. Of these, only very few are actually used in practice. This is partly due to the fact that desirable properties of an inhibitor usually extend beyond those simply related to metal protection. Considerations of cost, toxicity, availability and environmental friendliness are of considerable importance. Accordingly, the replacement of some toxic, expensive chemical inhibitors by inhibitors obtained from natural sources is necessary. Apart from being readily available, cheap and a renewable source of materials, naturally occurring substances are eco-friendly and ecologically acceptable. Naturally occurring substances are biodegradable and do not contain heavy metals or other toxic compounds.

Therefore, the present study of inhibition of Gnetum africana on copper corrosion and the optimization of the independent variables is necessary, as well as important to the environment.

The experiments dicussed in this work were designed to optimize the inhibition of copper by acid extract of Gnetum africana where several variables, including temperature, time and inhibitor concentration would influence the corrosion rate.

Design of experiment is a statistical procedure that can reduce significantly the number of experiment, keeping, however, the reliabilty of the conclusions at high standard. The traditional experiment method, one factor at a time approach can hardly be used to establish relationships among all the experimental input factors and the output responses. Even though the traditional approach can be useful in finding predominant factors in this situation, it is difficult to observe the optimum value of the working parameters as no interaction among them is considered. To solve this problem and obtain a probable optimum, design of experiment (DOE) offers a better alternative to study the effect of variables and their responses with minimum number of experiments [8] [9]. A factorial design is used to evaluate two or more factors simultaneously. The treatments are combinations of level of the factors. The advantages of factorial design over one-factor-at-a-time experiment are that they are more efficient and they allow interactions to be detected. Design expert 8.0.5.2 software provides a useful and powerful mathematical and statistical tool in order to develop the experimental planning and to analyse the results while aiming for a valid conclusion.

\section{Materials and Method}

\subsection{Metal Preparation}

The sheet employed in this work was made of pure copper (99.9\%).The copper sheet was mechanically pressed cut into different coupons of dimension $5 \times 1.5 \times 0.01 \mathrm{~cm}$. Each coupon polished and drilled at one end, was degreased in ethanol, dried in acetone and preserved in a desiccator. Solutions were prepared using analar grade reagents and distilled water.

\subsection{Extraction of Inhibitor}

Samples of the inhibitor were obtained from Akwata axis of Ogbete Main Market Enugu. The leaves were rinsed with distilled water, dried and ground. $1 \mathrm{~g}$ of ground inhibitor sample was soaked for $24 \mathrm{~h}$ in different concentrations ( $1 \mathrm{M}, 1.5 \mathrm{M}, 2 \mathrm{M}$ and $2.5 \mathrm{M}$ ) of $150-\mathrm{mL}$ of $\mathrm{HNO}_{3}$ to obtain a mixture. The mixture was filtered. The filtrate obtained from the mixture served as the stock solution of inhibitor extract. The same procedure was used to obtain extracts for $2 \mathrm{~g}$ and $3 \mathrm{~g}$ of the samples.

\subsection{Factorial Experimental Design and Optimization of Variables}

Inhibitor concentration, time of exposure and temperature were taken as independent variables, and the weight 
loss as the response. The experimental range and levels of independent variables for inhibition of copper corrosion are given in Table 1 . The design is based on a full factorial design with three categorical factors. If we have $\mathrm{k}$-factors, each run at 2-level, there will be $2^{\mathrm{k}}$ different combinations of the levels. In the present case, $\mathrm{k}$ is 3 and $2^{3}$ combinations (runs) would be generated. With inclusion of star and center points, a total of 27 runs and corresponding responses would be generated and displayed in design matrix of Table 2.

A single additional validation experiment was conducted using optimal input results obtained from Equation (1) and displayed in elsewhere in this work.

Table 1. Experimental range and levels of independent variables for inhibition of copper corrosion by acid extract of Gnetum africana.

\begin{tabular}{cccc}
\hline \multirow{2}{*}{ Independent Variables } & \multicolumn{3}{c}{ Range and Level } \\
\cline { 2 - 4 } & Lower Limit $(-1)$ & 0 & Upper Limit (1) \\
\hline Time $(\mathrm{hrs})(\times 1)$ & 24 & 72 & 120 \\
Inhibitor Concentration $(\mathrm{g} / \mathrm{L})(\times 2)$ & 0.001 & 0.002 & 0.003 \\
Temperature $(\mathrm{K})(\times 3)$ & 303 & 318 & 333 \\
\hline
\end{tabular}

Table 2. A $2^{3}$ full factorial design showing runs in actual factors for independent variables.

\begin{tabular}{|c|c|c|c|c|}
\hline Runs & Time (Min) & Inhibitor Concentration (g/L) & Temperature (K) & Response \\
\hline 1 & 72 & 0.001 & 333 & 3.54 \\
\hline 2 & 24 & 0.003 & 333 & 1.36 \\
\hline 3 & 24 & 0.001 & 318 & 0.96 \\
\hline 4 & 120 & 0.001 & 333 & 5.37 \\
\hline 5 & 72 & 0.003 & 303 & 1.32 \\
\hline 6 & 72 & 0.002 & 333 & 1.4 \\
\hline 7 & 120 & 0.002 & 303 & 2.18 \\
\hline 8 & 24 & 0.003 & 318 & 0.85 \\
\hline 9 & 24 & 0.002 & 333 & 1.72 \\
\hline 10 & 120 & 0.003 & 303 & 1.96 \\
\hline 11 & 72 & 0.003 & 333 & 2.88 \\
\hline 12 & 24 & 0.001 & 303 & 0.9 \\
\hline 13 & 72 & 0.002 & 303 & 1.4 \\
\hline 14 & 24 & 0.002 & 318 & 1.09 \\
\hline 15 & 120 & 0.002 & 333 & 4.84 \\
\hline 16 & 120 & 0.002 & 318 & 3.07 \\
\hline 17 & 72 & 0.003 & 318 & 1.64 \\
\hline 18 & 72 & 0.001 & 303 & 1.68 \\
\hline 19 & 72 & 0.002 & 318 & 1.95 \\
\hline 20 & 120 & 0.001 & 303 & 2.84 \\
\hline 21 & 24 & 0.003 & 303 & 0.62 \\
\hline 22 & 24 & 0.001 & 333 & 1.86 \\
\hline 23 & 120 & 0.003 & 318 & 2.67 \\
\hline 24 & 120 & 0.001 & 318 & 3.18 \\
\hline 25 & 24 & 0.002 & 303 & 0.7 \\
\hline 26 & 120 & 0.003 & 333 & 4.2 \\
\hline 27 & 72 & 0.001 & 318 & 2.02 \\
\hline
\end{tabular}




\section{Results and Discussion}

\subsection{Regression Analysis}

Figure 1 shows Half-Normal plot of the independent variables. From the Figure, the effect of time (effect $=$ 11.91 ) is much more significant than that temperature (effect $=8.41$ ) and inhibitor concentration (effect $=3.20)$. It can be concluded that the influence of time on the final response was obviously higher. One must attend to the period of immersion more to that of temperature and inhibitor concentration.

From Table 3, the Model F-value of 24.10 implies the model is significant. Values of p-values less than 0.0500 indicate the model terms to be significant. In this case A, B, C, AC are significant model terms. Values greater than 0.100 indicate the model terms are not significant. The fit of the model was checked with the coefficient of determination $R^{2}$. The predicated $R^{2}$ is 0.8227 which is in agreement with the adjusted $R^{2}$ of 0.08988 . Adequate precision measures the signal to noise ratio. A ratio greater than 4 is desirable. The calculated ratio is 18.175 which indicates an adequate signal. The polynomial equation describing the process in terms of denoted factors is expressed below as Equation (1)

$$
\begin{aligned}
Y_{\text {weight loss }}= & 2.16-1.04 X_{1}-0.17 X_{1}^{2}+0.33 X_{2}-0.12 X_{2}^{2}-0.64 X_{3} \\
& -0.22 X_{3}^{2}+0.27 X_{1} X_{2}+0.13 X_{1}^{2} X_{3}+0.068 X_{1} X_{3}^{2}+0.11 X_{1}^{2} X_{3}^{2}
\end{aligned}
$$

where $X_{1}, X_{2}$ and $X_{3}$ are time, inhibitor concentration and temperature, respectively.

\begin{tabular}{|c|c|c|c|c|c|}
\hline Sources & Sum of squares & Degree of freedom & Mean squares & F-values & P-values \\
\hline Model & 37.92 & 10 & 3.79 & 24.1 & 0.0001 \\
\hline Time $\left(X_{1}\right)$ & 23.19 & 2 & 11.6 & 73.68 & 0.0001 \\
\hline Inhibitor Conc $\left(X_{2}\right)$ & 1.49 & 2 & 0.75 & 4.74 & 0.0242 \\
\hline Temp $\left(X_{3}\right)$ & 10.88 & 2 & 5.44 & 34.56 & 0.0001 \\
\hline$X_{1} X_{2}$ & 2.36 & 4 & 0.59 & 3.76 & 0.0244 \\
\hline Residual & 2.52 & 16 & 0.16 & & \\
\hline Cor total & 40.44 & 26 & & & \\
\hline
\end{tabular}

Table 3. Anova report for selected factorial model.

Design-Expert $\circledast$ Software Weigth Loss

Shapiro-Wilk test p-value $=0.900$

A-value $=0$

A: Time

C: temperature

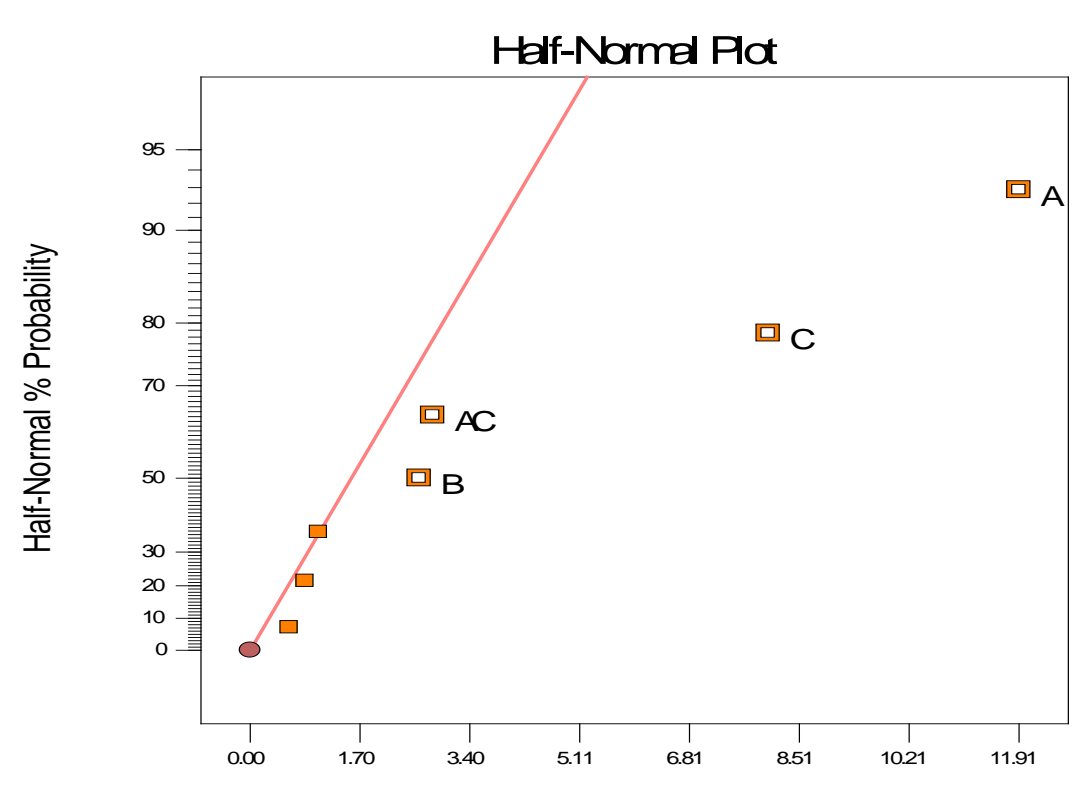

|Nommal Effect|

Figure 1. Half-normal plot for the effect of the independent variable. 
The effects of the factors and interactions on the response (weight loss) are shown in Figures 2-5. Figure 2 and Figure 3 show the one-factor plot showing the main effects of time and temperature, respectively. The effects are not usually interpreted because the factors (time and temperature) are involved in an interaction, hence, the warning on the plot. Interpretation can result in misleading information. Figure 4 shows the one-factor plot indicating the main effect of inhibitor concentration. From the plot it can be revealed that increase in inhibitor concentration resulted in the decrease in weight loss. Figure 5 shows the interaction between temperature and time. From the plot, the spread of points on the right side of the graph (where time is high) is larger than the spread between the points at the left side of the graph where time is low. In other words, the effect of temperature is less significant where time is low. Therefore, at a very low time of exposure, the effect of reaction temperature can be reduced, thus reducing the weight loss. Also, there exists generic increase in weight loss as temperature increases.
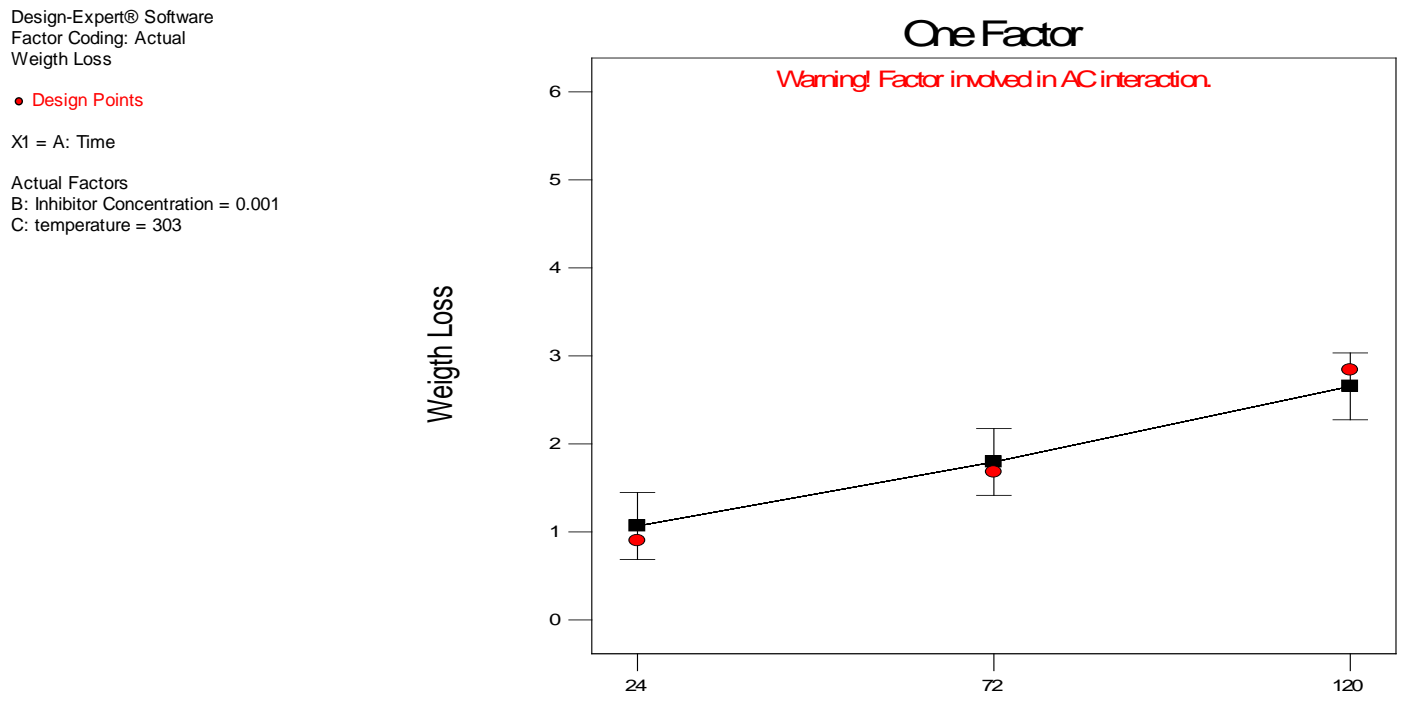

A Tirre

Figure 2. One-factor plot for the main effect of time.

Design-Expert@ Software Factor Coding: Actual Weigth Loss

- Design Points

X1 = C: temperature

Actual Factors A: Time $=24$

B: Inhibitor Concentration $=0.001$

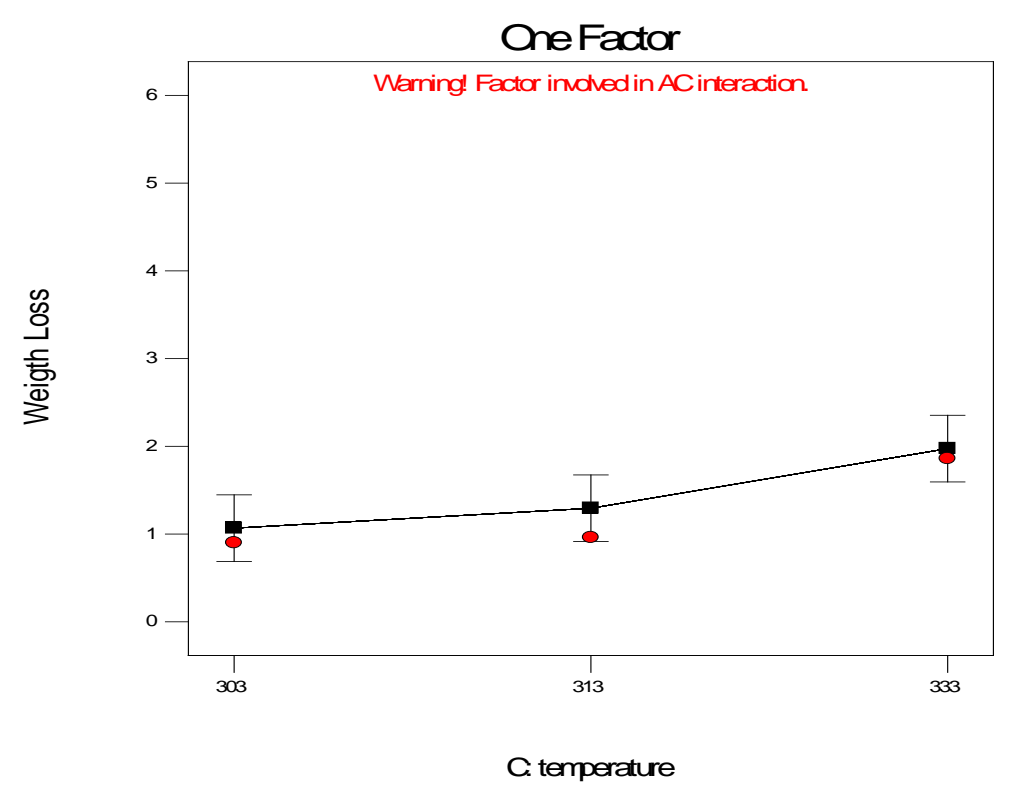

C. temperature

Figure 3. One-factor plot for the main effect of temperature. 
Design-Expert $\circledast$ Software Factor Coding: Actual Weigth Loss

- Design Points

$\mathrm{X} 1=\mathrm{B}$ : Inhibitor Concentration

Actual Factors

A: Time $=24$

C: temperature $=303$

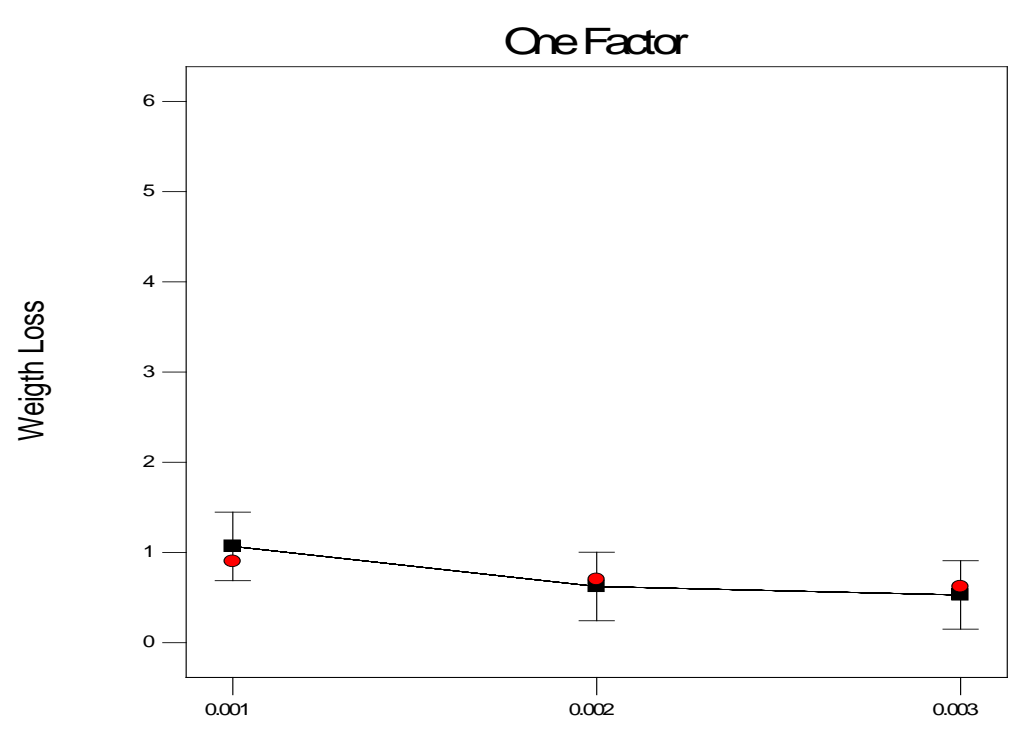

B: Inhibitor Concentration
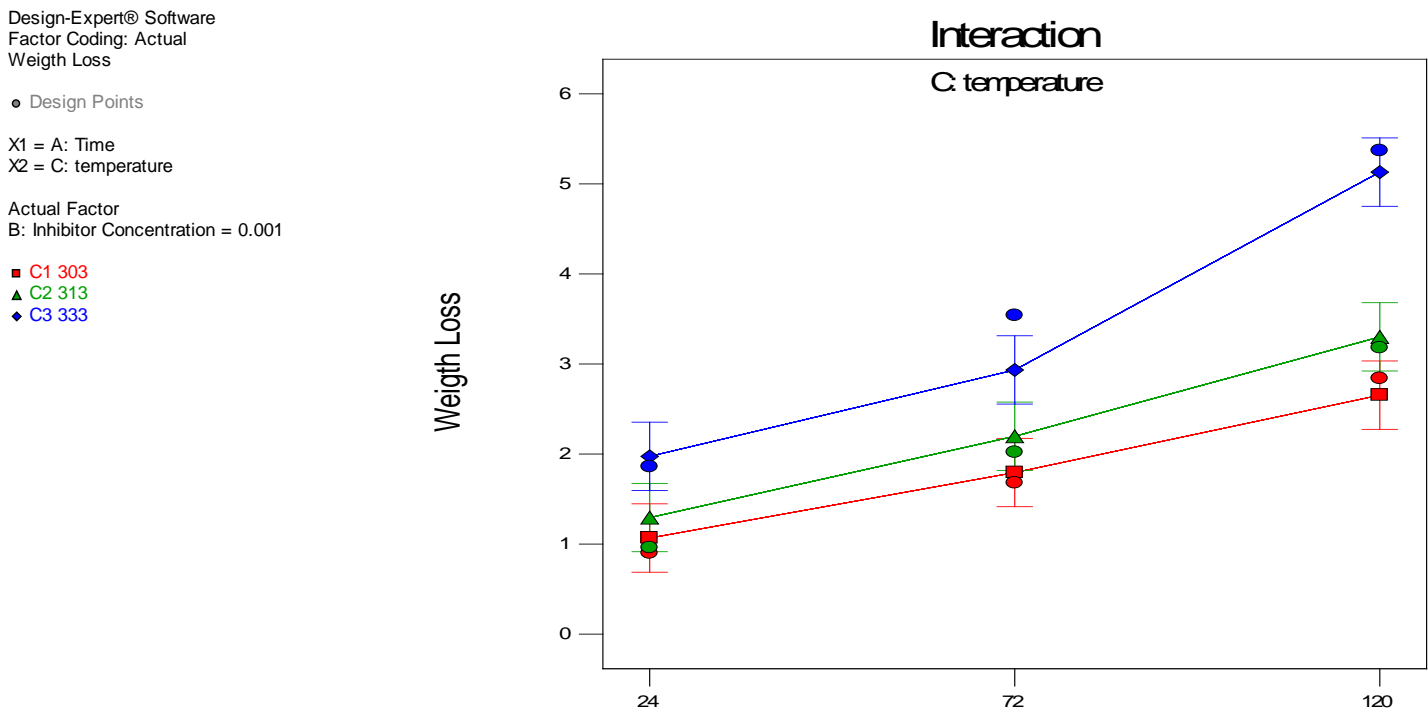

A Time

Figure 5. Interaction plot between temperature and time at various temperatures.

Figure 6 shows the response for interactive factors of temperature and time. Figure 7 shows the response for the interactive factors of inhibitor concentration and time. The 3D plots indicate that weight loss increases for any given inhibitor concentration with time. Higher inhibitor concentration and lower time of immersion reduced the rate of copper deterioration. This confirms that acid extract of Gnetum africana is an adsorption inhibitor for copper corrosion in $\mathrm{HNO}_{3}$ [10]-[14].

However, in reference to the work of Nkuzinna et al. [15], it was shown that the calculated values of corrosion rate in the absence of the inhibitor was higher compared to that in the presence of the inhibitor under the same experimental conditions. This confirmed that acid extracts of Gnetum africana actually inhibited the corrosion of copper in $\mathrm{HNO}_{3}$. Higher values of weight loss was highly enhanced at higher temperature and longer time of exposure (see Figure 6). 
Design-Expert® Software Factor Coding: Actual

Weigth Loss

- Design points above predicted value

- Design points below predicted value

$\mathrm{X} 1=\mathrm{A}:$ Time

$\mathrm{X} 2=\mathrm{C}:$ temperature

Actual Factor

B: Inhibitor Concentration $=0.001$
Figure 6. 3D plot for interaction between temperature and time.

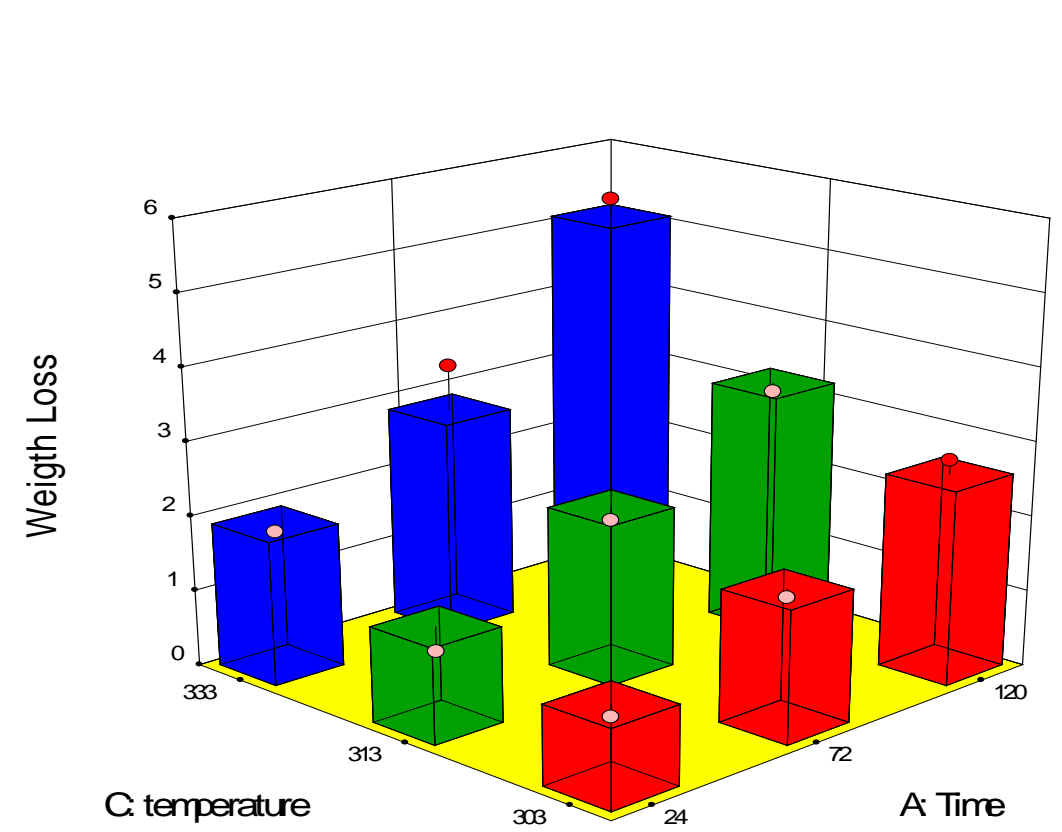

\footnotetext{
Design-Expert $\circledast$ Software

Factor Coding: Actual

Weigth Loss

- Design points above predicted value

$\mathrm{X} 1=\mathrm{A}$ : Time

$\mathrm{X}_{2}=\mathrm{B}:$ Inhibitor Concentration

Actual Factor

C: temperature $=303$
}

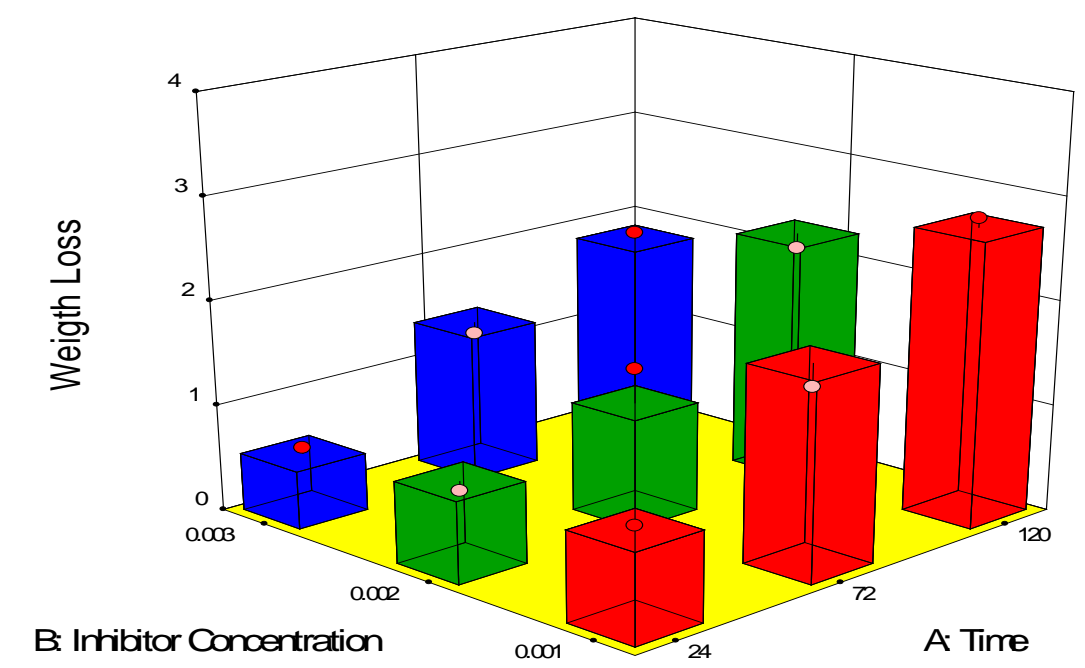

Figure 7. 3D plot for interaction on weight loss between inhibitor concentrations and time.

\subsection{Inhibition Optimization Result}

The optimum values of the selected variables (time, inhibitor concentration and temperature) were obtained by solving Equation (1). The optimum values of the input variables for minimum copper weight loss of $0.55 \mathrm{~g}$ are shown in Table 4. The ultimate goal in corrosion control is to reduce the rate of corrosion, which was maximally reduced at optimal results displayed in Table 4.

\subsection{Confirmation of Optimization Results}

In order to confirm the validity of optimization results obtained from the solution of Equation (1), one additional experimental run was carried out using the optimal results of input variables displayed in Table 4. The mini- 
Table 4. Optimum values of the process parameters for maximum efficiency.

\begin{tabular}{cc}
\hline Parameters & Optimum values \\
\hline Weight loss $(\mathrm{g})$ & 0.55 \\
Time $\left(X_{1}\right)(\mathrm{hrs})$ & 24 \\
Inhibition concentration $\left(X_{2}\right)(\mathrm{g} / \mathrm{l})$ & 0.003 \\
Temperature $\left(X_{3}\right)(\mathrm{K})$ & 303 \\
\hline
\end{tabular}

mum copper weight loss determined directly from the single confirmation experiment was $0.54 \pm 0.3$. The result is significantly close to the optimal weight loss determined from Equation (1). This shows that the use of DOE was appropriate for optimizing of selected process parameters.

Generally, however, the action of an inhibitor is based on adsorption mechanism. In this process inhibition action is assumed to be related to its adsorption at the metal/solution interface [16]. The adsorption of an organic adsorbate at a metal/solution interface can be regarded as a substitution adsorption process between the organic molecules in the aqueous solution $\mathrm{Org}_{(\text {(sol) }}$ and the water molecules on the metallic surface $\mathrm{H}_{2} \mathrm{O}_{\text {(ads) }}$. Equation (2) [17] amply demonstrates this process.

$$
\mathrm{Org}_{(\text {sol })}+\mathrm{xH}_{2} \mathrm{O}_{\text {(ads) }} \rightleftarrows \operatorname{Org}_{(\text {ads })}+\mathrm{xH}_{2} \mathrm{O}
$$

where: $\mathrm{x}$ is the size ratio representing the number of water molecules replaced by a molecule of organic adsorbate.

In order to achieve effective adsorption of an inhibitor on a surface of a metal, the interactive forces between metal and inhibitor interface must be greater than the interactive force of metal and water molecule interface [18]. Adsorption of inhibitor on metal interface follows, either physisorptionor chemisorption adsorptive mechanism.

\section{Conclusions}

The work studied the inhibition of copper using acid extract of Gnetum africana under various independent variables of time, inhibitor concentration and temperature. Consequently, employing design of experiment, it was possible to study the effects of the variables on corrosion rate. A full factorial design was successfully used for experimental design and analysis (27 assays). Prediction equation was derived for the process response. Solving the regression equation and with the help of the 3-D plots, it was possible to locate the optimum points. The optimum inhibition concentration, time and temperature were $0.003 \mathrm{~g} / \mathrm{L}, 24 \mathrm{~h}$ and $303 \mathrm{~K}$, respectively.

This research showed that factorial design of experiment was an efficient tool for predicting the effects of the independent variables on the process response.

\section{References}

[1] Ravari, F.B. (2009) Investigation of Two Salentype Schiff Base Compounds as Corrosion Inhibition of Copper in 0.5M $\mathrm{H}_{2} \mathrm{SO}_{4}$. Journal of Science, 22, 175-182.

[2] Noor, E.A. (2008) Comparative Study of Corrosion Inhibition of Mild Steel by Aqeous Extract of Fenugreek Seeds and Leaves in Acidic Solution. Journal of Engineering and Applied Sciences, 3, 23-30.

[3] Ebenso, E.E., Eddy, N.O. and Odongenyi, A.O. (2009) Inhibition of the Corrosion of Mild Steel by Methocarbamol. Portugaliae Electrochimica Acta, 27, 13-22.

[4] Ebenso, E.E., Eddy, N.O. and Odongenyi, A.O. (2008) Corrosion Inhibitive Properties and Adsorption Behaviour of Ethanol Extract of Piperguinensis as a Green Corrosion Inhibitor for Mild Steel in $\mathrm{H}_{2} \mathrm{SO}_{4}$. African Journal of Pure and Applied Chemistry, 4, 107-115.

[5] Oguzie, E.E. (2006) Adsorption and Corrosion Inhibitive Properties of Azadirachtaindica in Acid Solutions. Pigment and Resin Technology, 35, 334-340. http://dx.doi.org/10.1108/03699420610711335

[6] Gazquez, J.L. (2006) Quantum Chemical Study of the Inhibitive Properties of 2-Pyridyl-Azoles. The Journal of Physical Chemistry, 110, 8928-8934. http://dx.doi.org/10.1021/jp057143y

[7] Dubey, A.K. and Sing, G. (2007) Corrosion Inhibition of Mild Steel Using Brijj-30. Portugaliae Electrochimica Acta, 25, 205-219. http://dx.doi.org/10.4152/pea.200702205

[8] Montgomery, D.C. (2001) Design and Analysis of Experiments. 5th Edition, Wiley, New York. 
[9] Giovanilton, F.S., Fernando, L.C. and Andrea, L.O. (2011) Application of Surface Methodology for Optimization of Biodiesel Production by Transesterification of Soybean Oil with Ethanol. Fuel Processing Technology, 92, 407-413. http://dx.doi.org/10.1016/j.fuproc.2010.10.002

[10] Nkuzinna, O.C., Menkiti, M.C. and Onukwuli, O.D. (2011) Inhibition of Copper Corrosion by Acid Extract of Gnetum africana. International Journal of Multidisciplinary Science and Engineering, 2, 5-9.

[11] Abiola, O.K., Oforka, N.C. and Ebenso, E.E. (2007) Eco-Friendly Corrosion Inhibitors: Inhibitive Action of Delonixregia Extract for the Corrosion of Aluminium in Acidic Medium. Anti-Corrosion Methods \& Materials, 54, 219-224. http://dx.doi.org/10.1108/00035590710762357

[12] Okafor, P.C., Osabor, V. and Ebenso, E.E. (2007) Eco Friendly Corrosion Inhibitors: Inhibitive Action of Ethanol Extracts of Garcinia Kola for the Corrosion of Aluminum in Acidic Medium. Pigment and Resin Technology, 36, $299-305$. http://dx.doi.org/10.1108/03699420710820414

[13] Okafor, P.C. and Ebenso, E.E. (2007) Inhibitive Action of Carica Papaya Extracts on the Corrosion of Mild Steel in Acidic Media and Their Adsorption Characteristics. Pigment and Resin Technology, 36, 134-140. http://dx.doi.org/10.1108/03699420710748992

[14] Ita, B.I. (2005) Inhibition of Mild Steel Corrosion in Hydrochloric Acid by Anisaldehyde and Anisaldehyde Glycine. Bulletin of Electrochemistry, 21, 319-323.

[15] Zucchi, F. and Omar, I.H. (1985) Plant Extracts as Corrosion Inhibitors of Mild Steel in HCl Solution. Surface Technology, 24, 391-399. http://dx.doi.org/10.1016/0376-4583(85)90057-3

[16] Soltani, N., Tavakkoli, N., Khayatkashani, M., Jalali, M.R. and Mosavizade, A. (2012) Green Approach to Corrosion Inhibition of 304 Stainless Steel in Hydrochloric Acid Solution by the Extract of Saliva officinalis leaves. Corrosion Science, 62, 122-135.

[17] McCafferty, E. and Hackerman, N. (1972) Kinetics of Iron Corrosion in Concentrated Acidic Chloride Solutions. Journal of Electrochemical Society, 119, 999-1009.

[18] Sastri, V.S., Ghali, E. and Elboujdaini, M. (2007) Corrosion Prevention and Protection Practical Solutions. John Wiley \& Sons Ltd., 84. http://dx.doi.org/10.1002/9780470024546 